\title{
Epidemiology and outcomes of bloodstream infections in severe burn patients: a six-year retrospective study
}

Yangmin $\mathrm{Hu}^{1}$, Danyang $\mathrm{Li}^{2}$, Lingcheng $\mathrm{Xu}^{1}$, Yuping $\mathrm{Hu}^{3}$, Yiwen Sang ${ }^{4}$, Gensheng Zhang ${ }^{2}$ and Haibin Dai ${ }^{*}$

\begin{abstract}
Background: Infection is the leading cause of morbidity and mortality among burn patients, and bloodstream infection (BSI) is the most serious. This study aimed to evaluate the epidemiology and clinical outcomes of BSI in severe burn patients.

Methods: Clinical variables of all patients admitted with severe burns ( $\geq 20 \%$ total body surface area, \%TBSA) were analyzed retrospectively from January 2013 to December 2018 at a teaching hospital. The Kaplan-Meier method was utilized for plotting survival curves. Multivariate logistic regression and Cox regression model were also performed.

Results: A total of 495 patients were evaluated, of whom 136 (27.5\%) had a BSI. The median time from the patients being burned to BSI was 8 days. For BSI onset in these patients, 47.8\% (65/136) occurred in the first week. The most frequently isolated causative organism was A. baumannii (22.7\%), followed by methicillin-resistant Staphylococcus aureus (18.7\%) and K. pneumoniae (18.2\%), in patients with BSI. Multivariate logistic regression analysis showed that $\% \operatorname{TBSA}(p=0.023)$, mechanical ventilation ( $p=0.019)$, central venous catheter (CVC) $(p<0.001)$ and hospital length of stay ( $27 \mathrm{~d}$ vs $50 \mathrm{~d}, p<0.001$ ) were independent risk factors associated with $\mathrm{BSI}$. Cox regression model showed that acute kidney injury (HR, 12.26; 95\% Cl 2.31-64.98; $p=0.003)$ and septic shock (HR, 4.36; 95\% Cl 1.16-16.34; $p=0.031)$ were identified as independent predictors of 30-day mortality of BSI in burn patients.
\end{abstract}

Conclusions: Multidrug resistant gram-negative bacteria were the main pathogens of BSI in severe burn patients. Accurate evaluation of risk factors for BSI and the mortality of BSI in severe burn patients may improve early appropriate management.

Keywords: Burns, Bloodstream infection, Multidrug resistance, Mortality

\section{Introduction}

Infections are the leading cause of morbidity and mortality among burn patients [1, 2]. For patients with burns over $20 \%$ of the total body surface area (TBSA), the humoral and cellular immunity is also altered [3], and a disruption of the protective skin barrier and invasion of microorganisms into the burn eschar make the

*Correspondence: haibindai@zju.edu.cn

1 Department of Pharmacy, Second Affiliated Hospital, Zhejiang University School of Medicine, Hangzhou 310009, China

Full list of author information is available at the end of the article prevention and treatment of infection especially difficult [4]. One of the most troublesome infections that burn patients may develop is bloodstream infection (BSI) [5]. Burn patients are at a high risk of BSI because of multiple surgical procedures, the use of invasive devices and prolonged hospitalization [6]. Previous studies indicated that BSI was a predictor of poor outcome in burn patients [5, 7]. Therefore, it is essential to determine the characteristics of BSIs and find appropriate measures to prevent their occurrence.

Furthermore, due to rising antibiotic resistance worldwide, burn patients are at an increased risk of infections original author(s) and the source, provide a link to the Creative Commons licence, and indicate if changes were made. The images or other third party material in this article are included in the article's Creative Commons licence, unless indicated otherwise in a credit line to the material. If material is not included in the article's Creative Commons licence and your intended use is not permitted by statutory regulation or exceeds the permitted use, you will need to obtain permission directly from the copyright holder. To view a copy of this licence, visit http://creativecommons.org/licenses/by/4.0/. The Creative Commons Public Domain Dedication waiver (http://creativeco mmons.org/publicdomain/zero/1.0/) applies to the data made available in this article, unless otherwise stated in a credit line to the data. 
with multidrug-resistant (MDR) organisms, such as methicillin-resistant Staphylococcus aureus (MRSA), MDR P. aeruginosa, MDR A. baumannii and K. pneumoniae carbapenemase (KPC)-carrying strains $[8,9]$. These patients who were at risk for these MDR organisms also rely on broader-spectrum antibiotic agents, which further drive resistance by sustained selective pressure. Therefore, it is necessary to implement appropriate antibiotic therapy protocols in burn patients. This study was conducted at a burn ward to evaluate the epidemiology and risk factors associated with 30-day mortality due to BSI in severe burn patients.

\section{Methods}

\section{Study design and data collection}

This study was conducted at the Second Affiliated Hospital of Zhejiang University, School of Medicine, which is a tertiary care hospital. Patients including pediatric and adult were admitted to the burn ward or the burn intensive care unit during the period from January 2013 to December 2018. The patients included had a burn that covered $\geq 20 \%$ TBSA with or without inhalation injury. Patients who were admitted to the hospital more than $24 \mathrm{~h}$ after burn or died within $48 \mathrm{~h}$ after admission were excluded. The data collected for burn patients included demographic characteristics, comorbidities, type and extent of burn, inhalation injury, mechanical ventilation, hospital length of stay, coinfections before BSI, acute kidney injury (AKI), treatment of BSI, and outcomes.

\section{Definitions}

Severe burn was defined as those with burns greater than 20\% TBSA with or without inhalation injury. Only patients admitted to this facility within $24 \mathrm{~h}$ of sustaining the burn wound were included in the study. Bloodstream infection (BSI) was defined as the isolation of bacteria or fungi from one or more blood cultures. If patients had more than one positive blood culture of same species during the same admission episode, only the first BSI episode was included. For coagulase-negative Staphylococci, Corynebacterium spp., Bacillus and other common skin contaminants, at least two separate blood cultures with the same organisms were required to be positive for these to be considered as pathogens [10]. The definitions of skin infection, pneumonia, central venous catheter (CVC) and urinary tract infection (UTI) followed the relevant guidelines $[10,11]$. Empirical antimicrobial therapy was defined as a treatment administered to patients suspected of having bacteremia before microbiological results were available. Definitive therapy was defined as the treatment of antibiotics administered after obtaining susceptibility results. Appropriate therapy was defined as receiving at least one active antibiotic against the isolated pathogen within $48 \mathrm{~h}$, according to the results of species identification and susceptibility test.

\section{Microbiology}

Blood culture samples consisted of an aerobic bottle and an anaerobic bottle, and the two sets of samples were collected at two puncture sites. The blood culture bottles were incubated at approximately $37^{\circ} \mathrm{C}$ for up to 5 days in the semi-automated continuous monitoring blood culture system BacT/ALERT 3D (BioMérieux, France). Gram stain and subcultures on solid media were performed from positive blood cultures. Microbiology species identification and susceptibility testing were performed in the clinical laboratory by the VITEK 2 system (bioMérieux, France). MDR was defined as acquired nonsusceptibility to at least one agent in three or more antimicrobial categories [12].

\section{Statistical analysis}

Statistical analysis was performed using SPSS version 25.0. The chi-square test and Fisher's exact test were used to compare categorical variables. Continuous variables were described as the median and interquartile range (IQR), and differences were identified using the Student $T$ test or the Mann-Whitney $U$ test. Potential risk factors for BSI or mortality were evaluated by using univariate analysis, and those with a $p$ value $<0.1$ were further analyzed with multivariate logistic regression or Cox regression model to detect which factors were independently associated with BSI or mortality. The Kaplan-Meier method was utilized for plotting survival curves, and differences were compared using the log-rank test. All p values were two-tailed, and a $p$ value $<0.05$ was considered statistically significant.

\section{Results}

During the six-year study period, a total of 495 patients were evaluated, of whom 371 (74.9\%) were male. Their ages were between 13 and 99 years old (median 46 years, [IQR] 36-56 years). Most patients $(n=399,80.6 \%)$ were flame injuries. Of these patients, $88.5 \%(n=438)$ had accompanying third degree burns, and $42.8 \%(n=212)$ had inhalation injury. The median length of hospitalization was 35 days (IQR, 17-52 days) (Table 1 ).

There were $136(27.5 \%)$ patients who had a BSI during hospitalization. Univariate analysis showed that \%TBSA $(p<0.001)$, inhalation injury $(p<0.001)$, mechanical ventilation $((p<0.001), \mathrm{CVC}(p<0.001)$, AKI $(p=0.038)$ and hospital length of stay $(p<0.001)$ were associated with BSI. The results of multivariate logistic regression analysis showed that \%TBSA $(p=0.023)$, mechanical ventilation $(p=0.019), \mathrm{CVC}(p<0.001)$ and hospital length of stay $(p<0.001)$ were independent risk factors associated 
Table 1 Risk factors for BSI of the patients with burns over 20\% TBSA

\begin{tabular}{|c|c|c|c|c|c|c|}
\hline \multirow[t]{2}{*}{ Characteristic, n (\%) } & \multirow[t]{2}{*}{ Total $(n=495)$} & \multirow[t]{2}{*}{ Non-BSI $(n=359)$} & \multirow[t]{2}{*}{ BSI $(n=136)$} & \multirow{2}{*}{$\begin{array}{l}\text { Univariate } \\
\text { analysis } \\
p \text { value }\end{array}$} & \multicolumn{2}{|c|}{$\begin{array}{l}\text { Multivariate logistic } \\
\text { regression analysis }\end{array}$} \\
\hline & & & & & OR $(95 \% \mathrm{Cl})$ & $p$ value \\
\hline Male & $371(74.9)$ & $271(75.5)$ & $100(73.5)$ & 0.654 & - & - \\
\hline Age (median, IQR) & $46[36,56]$ & $46[35,56]$ & $47[37,56]$ & 0.728 & - & - \\
\hline Comorbidities & $121(24.4)$ & $87(24.2)$ & $34(25.0)$ & 0.859 & - & - \\
\hline \multicolumn{7}{|l|}{ Type of burn } \\
\hline Flame & $399(80.6)$ & $283(78.8)$ & $116(85.3)$ & 0.104 & - & - \\
\hline Chemical & $26(5.3)$ & $21(5.8)$ & $5(3.7)$ & 0.333 & - & - \\
\hline Hyperthermia liquid & $49(9.9)$ & $37(10.3)$ & $12(8.8)$ & 0.622 & - & - \\
\hline Other & $21(4.2)$ & $18(5.0)$ & $3(2.2)$ & 0.166 & - & - \\
\hline$\%$ TBSA & & & & & & 0.023 \\
\hline $20-39$ & $212(42.8)$ & $185(51.5)$ & $27(19.9)$ & $<0.001$ & - & - \\
\hline $40-59$ & $130(26.3)$ & $98(27.3)$ & $32(23.5)$ & & $1.08(0.55-2.09)$ & 0.828 \\
\hline $60-79$ & $64(12.9)$ & $31(8.6)$ & $33(24.3)$ & & $2.53(1.21-5.28)$ & 0.014 \\
\hline$\geq 80$ & $89(18.0)$ & $45(12.5)$ & $44(32.4)$ & & $2.24(1.01-4.97)$ & 0.048 \\
\hline Accompanying third degree burns & $438(88.5)$ & $312(86.9)$ & $126(92.6)$ & 0.078 & $0.70(0.29-1.69)$ & 0.423 \\
\hline Inhalation injury & $212(42.8)$ & $132(36.8)$ & $80(58.8)$ & $<0.001$ & $0.85(0.51-1.44)$ & 0.547 \\
\hline Mechanical ventilation & $178(36.0)$ & $96(26.7)$ & $82(60.3)$ & $<0.001$ & $1.97(1.12-3.47)$ & 0.019 \\
\hline CVC & $352(71.1)$ & $220(61.3)$ & $132(97.1)$ & $<0.001$ & $9.10(3.06-27.04)$ & $<0.001$ \\
\hline AKI & $56(11.3)$ & $34(9.5)$ & $22(16.2)$ & 0.038 & $0.80(0.38-1.67)$ & 0.550 \\
\hline Hospital length of stay, days (median, IQR) & $35[17,52]$ & $27[15,44]$ & $50[33,67]$ & $<0.001$ & $1.02(1.01-1.03)$ & $<0.001$ \\
\hline
\end{tabular}

$B S /$ bloodstream infection, IQR interquartile range, TBSA total body surface area, CVC Central venous catheter, AKI acute kidney injury

with BSI (Table 1). The median time from the patients being burned to the first episode of BSI was 8 days (IQR, 5-16 days). For BSI onset in these patients, 47.8\% $(65 / 136)$ occurred in the first week (Table 2).

Overall, there were 225 isolates from the bloodstream of 136 patients. Among them, 45.6\% (62/136) patients had more than one positive culture, so the number of cultures was higher than the number of patients. The most frequently isolated causative organism was $A$. baumannii (22.7\%), followed by MRSA (18.7\%) and K. pneumoniae $(18.2 \%)$ in patients with BSI (Table 3). Gram-negative bacteria were more common than Gram-positive bacteria. In these Gram-negative bacteria, most of them showed a MDR phenotype. Most (95\%) A. baumannii isolates were resistant to ceftazidime, cefepime, ciprofloxacin, piperacillin-tazobactam and carbapenems. The resistance frequencies of $K$. pneumoniae to amikacin and tigecycline were $52.8 \%$ and $24.0 \%$ respectively. All A. baumannii, K. pneumoniae and P. aeruginosa isolates were susceptible to polymyxin B. (Table 4).

Among the 136 patients with BSI, 58.1\% $(\mathrm{n}=79)$ patients received appropriate and $41.9 \%(n=57)$ received inappropriate, empirical antimicrobial therapy. A significant difference was found in skin coinfection before BSI $(p=0.021)$, multiple organ dysfunction syndrome (MODS) $(p=0.043)$ and inappropriate definitive therapy $(p=0.001)$ between the two groups (Table 5$)$. The 30-day and 60-day mortality were lower in the appropriate

Table 2 Duration from admission to the first episode of BSI in burn patients

\begin{tabular}{llll}
\hline Time after admission & Total $(\mathbf{n}=\mathbf{1 3 6})$ & Death $(\mathbf{n}=\mathbf{2 5})$ & Survival $(\mathbf{n}=\mathbf{1 1 1})$ \\
\hline 1st week & $65(47.8)$ & $11(44.0)$ & $54(48.6)$ \\
2nd week & $38(27.9)$ & $9(36.0)$ & $29(26.1)$ \\
3rd week & $19(14.0)$ & $4(16.0)$ & $15(13.5)$ \\
$\geq 4$ th week & $14(10.3)$ & $1(4.0)$ & $13(11.7)$ \\
$\begin{array}{l}\text { Duration from admission to bacteremia (days) } \\
\quad \text { (median, IQR) }\end{array}$ & $8[5-16]$ & $10[5-13.5]$ & $8[5-17]$ \\
\hline
\end{tabular}


Table 3 Causative organisms in burn patients with BSI

\begin{tabular}{ll}
\hline Pathogens & $\mathbf{n}(\mathbf{n}=\mathbf{2 2 5}) \mathbf{( \% )}$ \\
\hline A. baumannii & $51(22.7)$ \\
K. pneumoniae & $41(18.2)$ \\
P. aeruginosa & $22(9.8)$ \\
MRSA & $42(18.7)$ \\
MRCNS & $23(10.2)$ \\
Enterococcus species & $15(6.7)$ \\
Stenotrophomonas maltophilia & $7(3.1)$ \\
Escherichia coli & $7(3.1)$ \\
Enterobacter cloacae & $5(2.2)$ \\
Proteus mirabilis & $2(0.9)$ \\
Burkholderia cepacia & $2(0.9)$ \\
Morganella morganii & $1(0.4)$ \\
Ralstonia pickettii & $1(0.4)$ \\
Candida species & $6(2.7)$ \\
\hline
\end{tabular}

MRSA methicillin-resistant Staphylococcus aureus, MRCNS methicillin-resistant Coagulase negative staphylococci

empirical antimicrobial therapy group than in the inappropriate empirical antimicrobial therapy group (7.6\% vs $17.5 \%, p=0.076$, and $13.9 \%$ vs. $24.6 \%, p=0.114$, respectively), but there was no significant difference between the two groups. The Kaplan-Meier curves also showed no significant difference in the 30-day $(p=0.082)$ and 60 -day mortality $(p=0.129)$ between the two groups (Fig. 1).

By entering the \%TBSA $(p=0.001)$, mechanical ventilation $(p=0.021)$, AKI $(p<0.001)$, septic shock $(p<0.001)$, inappropriate empirical antimicrobial therapy $(p=0.093)$ and inappropriate definitive antimicrobial therapy $(p=0.010)$ in the Cox regression model, AKI (HR, 12.26; 95\% CI 2.31-64.98; $p=0.003$ ) and septic shock (HR, 4.36; $95 \%$ CI $1.16-16.34 ; p=0.031)$ were identified as independent predictors of 30-day mortality of BSI in burn patients (Table 6).

\section{Discussion}

Invasive infection, especially BSI, is now the chief reason for morbidity and mortality after burn injury $[1,13]$. Patel BM et al. found that $4 \%$ of examined burn patients developed a BSI [5]. However, our study found that $27.5 \%$ of the burn patients developed a BSI, probably because we only included serious burn patients with a burn extent $\geq 20 \%$ TBSA. We found that the median time from the patients being burned to BSI was 8 days and that $47.8 \%$ of BSIs occurred in the first week. This finding was similar to the results found in other studies that demonstrated the median time from burn to BSI to be 7 days [5] or 6 days [14]. Thus, it is important to control infection in the first week after the hospitalization of burn patients.

Our study showed that \%TBSA, mechanical ventilation, CVC use and hospital length of stay were independent risk factors associated with BSI. Burn is independently associated with the development of nosocomial BSI [15], and the incidence of BSI increases with \%TBSA $[4,16]$. However, burn wounds are not the only point of entrance for pathogens that cause BSI [7]. Other factors, such as CVC use, other infections and receipt of mechanical ventilation, should be considered to be associated with BSI [17]. It has been identified that CVC is the most frequent cause of nosocomial BSI $[14,18]$. Mechanical ventilation and prolonged hospital stay increase the likelihood of exposure to nosocomial infections including BSI, which complicates the treatment of the patients $[19,20]$. The implementation of the various active prevention strategies is essential to reduce BSI and improves the prognosis of burn patients. Intervention measures should include optimal care, strict hand hygiene, reduction of

Table 4 Antibiotic resistance in Gram-negative isolates of BSI

\begin{tabular}{|c|c|c|c|}
\hline Antibiotics & A. baumannii, $\%$ resistant $(n=51)$ & K. pneumoniae, $\%$ resistant $(n=41)$ & $\begin{array}{l}\text { P. aeruginosa, \% } \\
\text { resistant }(n=22)\end{array}$ \\
\hline Amikacin & 75.0 & 52.8 & 45.0 \\
\hline Ceftazidime & 95.0 & 88.9 & 30.0 \\
\hline Cefepime & 95.0 & 80.6 & 65.0 \\
\hline Ciprofloxacin & 95.0 & 86.1 & 50.0 \\
\hline Levofloxacin & 72.5 & 80.6 & 55.0 \\
\hline Imipenem & 95.0 & 77.8 & 75.0 \\
\hline Meropenem & 95.0 & 77.8 & 75.0 \\
\hline Cefoperazone-Sulbactam & 72.5 & 88.9 & 80.0 \\
\hline Piperacillin-Tazobactam & 95.0 & 80.6 & 80.0 \\
\hline Tigecycline & $11.4(n=45)$ & $24.0(n=29)$ & - \\
\hline Polymyxin B & $0.0(n=21)$ & $0.0(n=18)$ & $0.0(n=9)$ \\
\hline
\end{tabular}


Table 5 Differences of characteristics of BSI burn patients receiving appropriate and inappropriate empirical antimicrobial therapy

\begin{tabular}{|c|c|c|c|}
\hline \multirow[t]{2}{*}{ Variable } & \multicolumn{3}{|c|}{ Empirical antimicrobial therapy } \\
\hline & $\begin{array}{l}\text { Appropriate } \\
\mathrm{n}=79\end{array}$ & $\begin{array}{l}\text { Inappropriate } \\
n=57\end{array}$ & $p$-value \\
\hline Male & $59(74.7)$ & $41(71.9)$ & 0.719 \\
\hline Age (years) (median, IQR) & $47[34,54]$ & $46[38,56]$ & 0.601 \\
\hline Comorbidities & $19(24.1)$ & $15(26.3)$ & 0.763 \\
\hline \multicolumn{4}{|l|}{ Type of burn } \\
\hline Flame & 70 (88.6) & $46(80.7)$ & 0.199 \\
\hline Chemical & $2(2.5)$ & $3(5.3)$ & 0.404 \\
\hline Hyperthermia liquid & $5(6.3)$ & $7(12.3)$ & 0.227 \\
\hline Other & $2(2.5)$ & $1(1.8)$ & 0.761 \\
\hline \multicolumn{4}{|l|}{$\%$ TBSA } \\
\hline 20-39 & $16(20.3)$ & $11(19.3)$ & 0.341 \\
\hline $40-59$ & $19(24.1)$ & $13(22.8)$ & \\
\hline $60-79$ & $23(29.1)$ & $10(17.5)$ & \\
\hline$\geq 80$ & $21(26.6)$ & $23(40.4)$ & \\
\hline Accompanying third degree burns & $73(92.4)$ & $53(93.0)$ & 0.899 \\
\hline Inhalation injury & $51(64.6)$ & $29(50.9)$ & 0.110 \\
\hline Mechanical ventilation & $48(60.8)$ & $34(59.6)$ & 0.896 \\
\hline \multicolumn{4}{|l|}{ Coinfections before bacteremia } \\
\hline Skin infection & $65(82.3)$ & $37(64.9)$ & 0.021 \\
\hline Pneumonia & $38(48.1)$ & $19(33.3)$ & 0.085 \\
\hline CVC infection & $24(30.4)$ & $14(24.6)$ & 0.456 \\
\hline UTI & $3(3.8)$ & $3(5.3)$ & 0.681 \\
\hline AKI & $9(11.4)$ & $13(22.8)$ & 0.074 \\
\hline Septic shock & $9(11.4)$ & $9(15.8)$ & 0.455 \\
\hline MODS & $7(8.9)$ & $12(21.1)$ & 0.043 \\
\hline Hospital length of stay, days (median, IQR) & $51[34,68]$ & $47[30,66]$ & 0.642 \\
\hline Inappropriate definitive antimicrobial therapy & $3(3.8)$ & $13(22.8)$ & 0.001 \\
\hline \multicolumn{4}{|l|}{ Outcomes } \\
\hline 30-day mortality & $6(7.6)$ & $10(17.5)$ & 0.076 \\
\hline 60-day mortality & $11(13.9)$ & $14(24.6)$ & 0.114 \\
\hline
\end{tabular}

$B S /$ bloodstream infection, IQR interquartile range, TBSA total body surface area, CVC central venous catheter, UTI urinary tract infection, AKI acute kidney injury, MODS multiple organ dysfunction syndrome

mechanical ventilation duration, antimicrobial therapies and continuous monitoring of infection development [21, 22].

Some studies found that Gram-positive organisms, particularly Staphylococcus aureus, were more commonly associated with BSI than Gram-negative organisms [5, 23], whereas other studies showed that $P$. aeruginosa was the most prevalently isolated species from burn patients $[24,25]$. However, we found that $A$. baumannii was the most common organism isolated from burn patients with BSI, followed by MRSA and K. pneumoniae. At another Chinese burn institute, the resistance frequencies of $A$. baumannii isolated from the BSI of burn patients to imipenem and meropenem were $94 \%$ and $91 \%$, respectively [26], which are close to our result, 95\%. MDR organism infections resulted in a increased length of hospitalization, elevated need for mechanical ventilation and prolonged duration of antibiotic treatment [8]. These data emphasized that additional attention should be paid to monitoring the local microbiology and antimicrobial susceptibility test reports for medical institutions to prevent further distribution.

One of the major challenges in treating BSI is bacterial resistance to antibiotics, and appropriate therapy is associated with protective effect on mortality [27]. Even if there is no proven infection, antibiotic therapy is often used as an empirical measure for burn patients according to the symptoms and signs of infection [28], or due to other infections such as skin infection or pneumonia before BSI. In our study, $58.1 \%(n=79)$ of severe burns 

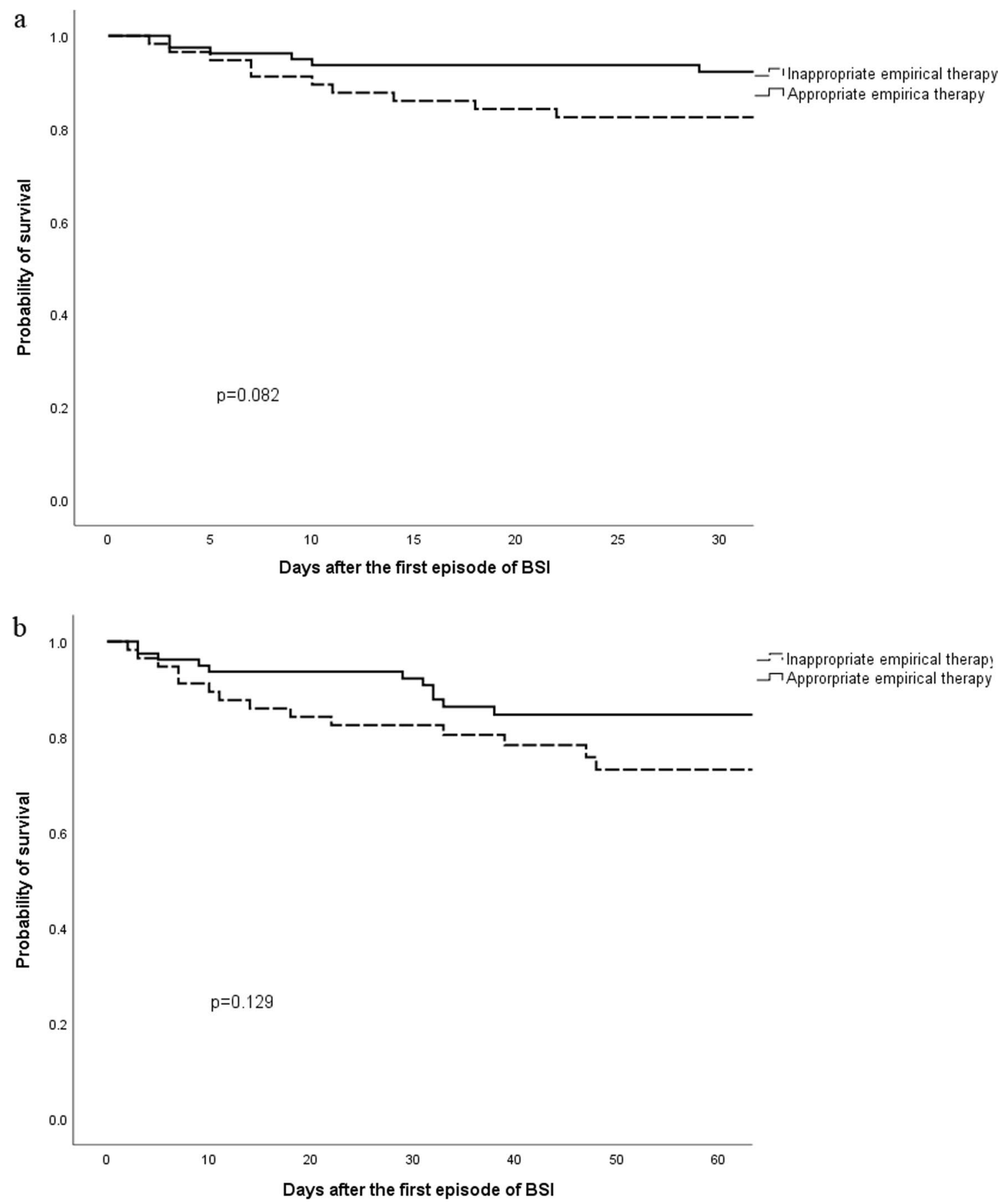

Fig. 1 Kaplan-Meier curves of 30-day mortality (a) and 60-day mortality (b) according empiric therapy for BSI in burn patients

patients with BSI received appropriate empirical antimicrobial therapy. MODS in the appropriate empirical antimicrobial therapy group was significantly lower than that in the inappropriate empirical antimicrobial therapy group. For burn patients, MODS was recognized as a leading cause of death [8]. However, the mortality in patients who did receive appropriate empirical therapy was not better than the mortality in patients who received inappropriate empirical therapy in our study, though a possible trend was noted. It was possible that the sample size in our study was too small to demonstrate whether inappropriate therapy was associated with 
Table 6 Univariate and multivariate Cox regression analyses of variables associated with 30-day mortality of BSI in burn patients

\begin{tabular}{|c|c|c|c|c|}
\hline \multirow[t]{2}{*}{ Variable } & \multicolumn{2}{|l|}{ Crude analysis } & \multicolumn{2}{|l|}{ Adjusted analysis } \\
\hline & $\mathrm{HR}(95 \% \mathrm{Cl})$ & $p$ value & $\mathrm{HR}(95 \% \mathrm{Cl})$ & $p$ value \\
\hline Male & $0.70(0.20-2.47)$ & 0.583 & & \\
\hline Age & $1.00(0.97-1.04)$ & 0.856 & & \\
\hline Comorbidities & $0.72(0.21-2.53)$ & 0.609 & & \\
\hline Type of burn (Flame) & $0.52(0.17-1.60)$ & 0.253 & & \\
\hline$\geq 80 \%$ TBSA & $0.14(0.05-0.44)$ & 0.001 & $0.86(0.22-3.38)$ & 0.861 \\
\hline Accompanying third degree burns & $22.7(0.01,7204.37)$ & 0.448 & & \\
\hline Inhalation injury & $1.55(0.54-4.46)$ & 0.417 & & \\
\hline Mechanical ventilation & $10.77(1.42-81.54)$ & 0.021 & $4.14(0.41-41.53)$ & 0.228 \\
\hline \multicolumn{5}{|l|}{ Coinfections before bacteremia } \\
\hline Skin infection & $0.72(0.25-2.08)$ & 0.546 & & \\
\hline Pneumonia & $1.40(0.53-3.72)$ & 0.503 & & \\
\hline CVC infection & $0.36(0.08-1.57)$ & 0.171 & & \\
\hline UTI & $1.43(0.19-10.84)$ & 0.728 & & \\
\hline AKI & $42.85(12.10-151.78)$ & $<0.001$ & $12.26(2.31-64.98)$ & 0.003 \\
\hline Septic shock & $36.98(12.79-106.87)$ & $<0.001$ & $4.36(1.16-16.34)$ & 0.031 \\
\hline Inappropriate empirical antimicrobial therapy & $0.42(0.15-1.16)$ & 0.093 & $0.56(0.17-1.89)$ & 0.351 \\
\hline Inappropriate definitive antimicrobial therapy & $0.25(0.09-0.72)$ & 0.010 & $0.52(0.12-2.19)$ & 0.371 \\
\hline
\end{tabular}

$H R$ hazard ratio, $\mathrm{Cl}$ confidence interval, TBSA total body surface area, CVC central venous catheter, UTI urinary tract infection, AKI acute kidney injury

mortality. Most BSIs treated inappropriately were caused by MDR Gram-negative organisms.

Severe infections causing septic shock occur frequently in burn patients and AKI is also a common complication in these patients. In this study, both septic shock and AKI were shown to be the risk factors for 30-day mortality of BSI in severe burn patients. Other works support our finding that the AKI and septic shock significantly increased the mortality in burn patients [29-31].

The current study has some potential limitations. First, the cultures from skin lesions were considered as being episodes of skin coinfection, but the organisms isolated from these cultures may have been colonisers and were not necessarily causing infection. Second, coinfection was quite common during hospitalization of patients, so we could not identify which specific organism caused mortality with BSI. Third, we did not analyze the impact of MDR organisms on mortality or other clinical outcomes because most of the isolated bacteria were MDR; however, this effect can be a focus of future research. Finally, we cannot exclude that confounding factors were potentially associated with the mortality of BSI in burn patients, although we had considered as many factors as possible.

\section{Conclusions}

This study demonstrated that MDR gram-negative bacteria were the main pathogens of BSI in severe burn patients. Mechanical ventilation, \%TBSA, CVC and hospital length of stay were independent risk factors associated with BSI, and AKI and septic shock were identified as the independent predictors of 30-day mortality of BSI in burn patients. Accurate evaluation of risk factors for BSI and the mortality of BSI in severe burn patients may improve early appropriate management. Additional studies and greater sample size are needed to further investigate the potential impact of appropriate antibiotic treatment on mortality.

\section{Acknowledgements}

Not applicable.

\section{Authors' contributions}

YM contributed to the conception and design of the study and writing to the initial draft of the paper. LC and YP contributed to the acquisition and analysis of the data. DY and GS contributed to the revision of the important intellectual content. YW contributed to analyze the microbiology results and susceptibility testing. HB contributed to the concept of the study and final approval of the version to be submitted. All authors read and approved the final manuscript.

Funding

This research was supported by the Zhejiang Provincial Natural Science Foundation of China [Grant Number: LY15H310006].

\section{Availability of data and materials}

All data generated or analyzed during this study were included in this manuscript.

\section{Declarations}

\section{Ethics approval and consent to participate}

This study was approved by the Ethics Committee of the 2nd Affiliated Hospital, School of Medicine, Zhejiang University (No. 2019-417). Due to the retrospective nature of the study, informed consent was waived. 


\section{Consent for publication \\ Not applicable.}

\section{Competing interests}

The authors report no conflicts of interest.

\section{Author details}

${ }^{1}$ Department of Pharmacy, Second Affiliated Hospital, Zhejiang University School of Medicine, Hangzhou 310009, China. ${ }^{2}$ Department of Critical Care Medicine, Second Affiliated Hospital, Zhejiang University School of Medicine, Hangzhou 310009, China. ${ }^{3}$ Department of Pharmacy, Hangzhou Third People's Hospital, Hangzhou 310009, China. ${ }^{4}$ Department of Laboratory Medicine, Second Affiliated Hospital, Zhejiang University School of Medicine, Hangzhou 310009, China.

Received: 4 May 2020 Accepted: 15 June 2021

Published online: 30 June 2021

\section{References}

1. Greenhalgh DG, Saffle JR, Holmes JHT, Gamelli RL, Palmieri TL, Horton JW, Tompkins RG, Traber DL, Mozingo DW, Deitch EA, et al. American Burn Association consensus conference to define sepsis and infection in burns. J Burn Care Res. 2007;28(6):776-90.

2. Church D, Elsayed S, Reid O, Winston B, Lindsay R. Burn wound infections. Clin Microbiol Rev. 2006;19(2):403-34.

3. Faunce DE, Gamelli RL, Choudhry MA, Kovacs EJ. A role for CD1drestricted NKT cells in injury-associated T cell suppression. J Leukoc Biol. 2003;73(6):747-55.

4. Barret JP, Herndon DN. Effects of burn wound excision on bacterial colonization and invasion. Plast Reconstr Surg. 2003, 111(2):744-50; discussion 751-742.

5. Patel BM, Paratz JD, Mallet A, Lipman J, Rudd M, Muller MJ, Paterson DL, Roberts JA. Characteristics of bloodstream infections in burn patients: an 11-year retrospective study. Burns. 2012;38(5):685-90.

6. Brusselaers N, Monstrey S, Snoeij T, Vandijck D, Lizy C, Hoste E, Lauwaert S, Colpaert K, Vandekerckhove L, Vogelaers D, et al. Morbidity and mortality of bloodstream infections in patients with severe burn injury. Am J Crit Care. 2010;19(6):e81-87.

7. Shupp JW, Pavlovich AR, Jeng JC, Pezzullo JC, Oetgen WJ, Jaskille AD, Jordan $\mathrm{MH}$, Shoham S. Epidemiology of bloodstream infections in burninjured patients: a review of the national burn repository. J Burn Care Res. 2010;31(4):521-8.

8. van Langeveld I, Gagnon RC, Conrad PF, Gamelli RL, Martin B, Choudhry MA, Mosier MJ. Multiple-drug resistance in burn patients: a retrospective study on the impact of antibiotic resistance on survival and length of stay. J Burn Care Res. 2017;38(2):99-105.

9. Alaghehbandan R, Azimi L, Rastegar Lari A. Nosocomial infections among burn patients in Teheran, Iran: a decade later. Ann Burns Fire Disasters. 2012:25(1):3-7

10. Horan TC, Andrus M, Dudeck MA. CDC/NHSN surveillance definition of health care-associated infection and criteria for specific types of infections in the acute care setting. Am J Infect Control. 2008;36(5):309-32.

11. Kalil AC, Metersky ML, Klompas M, Muscedere J, Sweeney DA, Palmer LB, Napolitano LM, O'Grady NP, Bartlett JG, Carratala J, et al. Management of adults with hospital-acquired and Ventilator-associated Pneumonia: 2016 Clinical Practice Guidelines by the Infectious Diseases Society of America and the American Thoracic Society. Clin Infect Dis. 2016;63(5):e61-111.

12. Magiorakos AP, Srinivasan A, Carey RB, Carmeli Y, Falagas ME, Giske CG, Harbarth S, Hindler JF, Kahlmeter G, Olsson-Liljequist B, et al. Multidrugresistant, extensively drug-resistant and pandrug-resistant bacteria: an international expert proposal for interim standard definitions for acquired resistance. Clin Microbiol Infect Dis. 2012;18(3):268-81.

13. Williams FN, Herndon DN, Hawkins HK, Lee JO, Cox RA, Kulp GA, Finnerty CC, Chinkes DL, Jeschke MG. The leading causes of death after burn injury in a single pediatric burn center. Crit Care (London, England). 2009;13(6):R183.

14. Ramirez-Blanco CE, Ramirez-Rivero CE, Diaz-Martinez LA, Sosa-Avila LM. Infection in burn patients in a referral center in Colombia. Burns: J Int Soc Burn Injuries. 2017:43(3):642-53.
15. Laupland K, Gregson DB, Kirkpatrick AW, Kortbeek JB, Zygun DA, Findlay C, Hameed SM. Bloodstream infection complicating trauma. Clin Invest Med. 2004;27(5):253-8.

16. Rech MA, Mosier MJ, McConkey K, Zelisko S, Netzer G, Kovacs EJ, Afshar M. Outcomes in burn-injured patients who develop sepsis. J Burn Care Res. 2019;40(3):269-73.

17. Al-Rawajfah OM, Stetzer F, Hewitt JB. Incidence of and risk factors for nosocomial bloodstream infections in adults in the United States, 2003. Infect Control Hosp Epidemiol. 2009;30(11):1036-44.

18. Safdar N, Fine JP, Maki DG. Meta-analysis: methods for diagnosing intravascular device-related bloodstream infection. Ann Intern Med. 2005;142(6):451-66

19. Gomez R, Murray CK, Hospenthal DR, Cancio LC, Renz EM, Holcomb JB, Wade CE, Wolf SE. Causes of mortality by autopsy findings of combat casualties and civilian patients admitted to a burn unit. J Am Coll Surg. 2009;208(3):348-54.

20. Carr JA, Phillips BD, Bowling WM. The utility of bronchoscopy after inhalation injury complicated by pneumonia in burn patients: results from the National Burn Repository. J Burn Care. 2009;30(6):967-74.

21. Velasquez Reyes DC, Bloomer M, Morphet J. Prevention of central venous line associated bloodstream infections in adult intensive care units: a systematic review. Intensive Crit Care Nurs. 2017:43:12-22.

22. Zilberberg MD, Nathanson BH, Ways J, Shorr AF. Characteristics, hospital course, and outcomes of patients requiring prolonged acute versus short-term mechanical ventilation in the United States, 2014-2018. Crit Care Med. 2020;48(11):1587-94.

23. Sakabe D, Del Fiol FS. Profile of infections and antimicrobial treatment among burn-injury patients. Am J Infect Control. 2016;44(8):950-2.

24. Soleymanzadeh-Moghadam S, Azimi L, Amani L, Rastegar Lari A, Alinejad F, Rastegar Lari A. Analysis of antibiotic consumption in burn patients. GMS Hygiene infection Control 2015, 10:Doc09.

25. Khorasani G, Salehifar E, Eslami G. Profile of microorganisms and antimicrobial resistance at a tertiary care referral burn centre in Iran: emergence of Citrobacter freundii as a common microorganism. Burns: J Int Soc Burn Injuries. 2008:34(7):947-52.

26. Huang G, Yin S, Xiang L, Gong Y, Sun K, Luo X, Zhang C, Yang Z, Deng L, Jiang $B$, et al. Epidemiological characterization of Acinetobacter baumannii bloodstream isolates from a Chinese Burn Institute: A three-year study. Burns: J Int Soc Burn Injuries. 2016;42(7):1542-7.

27. Gutierrez-Gutierrez B, Salamanca E, de Cueto M, Hsueh PR, Viale P, Pano-Pardo JR, Venditti M, Tumbarello M, Daikos G, Canton R, et al. Effect of appropriate combination therapy on mortality of patients with bloodstream infections due to carbapenemase-producing Enterobacteriaceae (INCREMENT): a retrospective cohort study. Lancet Infect Dis. 2017;17(7):726-34

28. Bahemia IA, Muganza A, Moore R, Sahid F, Menezes CN. Microbiology and antibiotic resistance in severe burns patients: $A 5$ year review in an adult burns unit. Burns: J Int Soc Burn Injuries. 2015;41(7):1536-42.

29. Brusselaers N, Monstrey S, Colpaert K, Decruyenaere J, Blot SI, Hoste EA. Outcome of acute kidney injury in severe burns: a systematic review and meta-analysis. Intensive Care Med. 2010;36(6):915-25.

30. Chung KK, Coates EC, Smith DJ Jr, Karlnoski RA, Hickerson WL, ArnoldRoss AL, Mosier MJ, Halerz M, Sprague AM, Mullins RF, et al. High-volume hemofiltration in adult burn patients with septic shock and acute kidney injury: a multicenter randomized controlled trial. Critical Care (London, England). 2017;21(1):289.

31. Mariano F, Hollo Z, Depetris N, Malvasio V, Mella A, Bergamo D, Pensa A, Berardino M, Stella M, Biancone L. Coupled-plasma filtration and adsorption for severe burn patients with septic shock and acute kidney injury treated with renal replacement therapy. Burns : J Int Soc Burn Injuries. 2020;46(1):190-8.

\section{Publisher's Note}

Springer Nature remains neutral with regard to jurisdictional claims in published maps and institutional affiliations. 